\title{
Sumari
}

Papers. Revista de Sociologia

Octubre-desembre 2011, vol. 96, núm. 4, p. 1015-1396, ISSN 0210-2862

Les paraules clau són en llenguatge lliure

http://ddd.uab.cat/record/35

1019-1020 Nota de la redacció

1021-1022 Presentació

\section{Articles Monogràfic}

Canvis en la relació educació-treball i en el comportament dels actors implicats

1025-1045 SALA, Guillem (Universitat Autònoma de Barcelona)

Approaches to Skills Mismatch in the Labour Market: A Literature Review. Papers, 2011, vol. 96, núm. 4, p. 1025-1045.

Key words: labour market; mismatch; skills; competences; overeducation.

1047-1073 PlanAS, Jordi (Universitat Autònoma de Barcelona)

La relación entre educación y empleo en Europa. Papers, 2011, vol. 96, núm. 4, p. 1047-1073.

Palabras clave: relación entre educación y empleo; competencias; modelos de producción de competencias; análisis comparado; cambios institucionales; actores.

1075-1096 GreEN, Andy (University of London)

Modelos de formación a lo largo de toda la vida y la «sociedad del conocimiento» en Europa. Papers, 2011, vol. 96, núm. 4, p. 1075-1096.

Palabras clave: formación a lo largo de toda la vida; competitividad; cohesión social.

1097-1123 LASSNIGG, Lorenz (Institute for Advanced Studies)

Matching Education and Training to Employment: Practical Problems and Theoretical Solutions - Or the Other Way Round? Papers, 2011, vol. 96, núm. 4, p. 1097-1123.

Key words: education-and-training and employment coordination; matching theories; Austrian practices and policies. 


\section{5-1138 GERME, Jean-François (CNAM. LISE)}

Projet professionnel et Incertitude sur le marché du travail. Papers, 2011, vol. 96, núm. 4, p. 1125-1138.

Mots clés : incertitude; fléxibilité; projet; comportements des jeunes; formation.

\section{9-1162 CASAL, Joaquim; MERINO, Rafael; GarCía, Maribel (Universitat} Autònoma de Barcelona)

Pasado y futuro del estudio sobre la transición de los jóvenes. Papers, 2011, vol. 96, núm. 4, p. 1139-1162.

Palabras clave: juventud; transición; biografía; trayectoria; itinerario; inserción; emancipación.

1163-1185 RAFFE, David (The University of Edinburgh. Centre for Educational Sociology) Itinerarios que relacionan educación con trabajo. Revisión de conceptos, investigación y debates políticos. Papers, 2011, vol. 96, núm. 4, p. 1163-1185.

Palabras clave: transición escuela-trabajo, itinerarios formativos, política educativa.

1187-1203 PAgnossin, Elisabetta; ARMI, Franca (Institut de recherche et documentation pédagogique)

Transition entre la formation et le monde du travail. État de la recherche en Suisse. Papers, 2011, vol. 96, núm. 4, p. 1187-1203.

Mots clés : transition formation-travail; tendances de recherche; Suisse.

1205-1233 DÁvILA, Oscar; GHIARDo, Felipe (Centro de Estudios Sociales) Trayectorias sociales juveniles. Cursos y discursos sobre la integración laboral. Papers, 2011, vol. 96, núm. 4, p. 1205-1233.

Palabras clave: sociología de la juventud; integración social; integración laboral.

1235-1255 Troiano, Helena; Masjuan, Josep Maria; Elias, Marina (Universitat Autònoma de Barcelona)

Estrategias de gestión y comunicación de los líderes intermedios en la aplicación de los ECTS. Papers, 2011, vol. 96, núm. 4, p. 1235-1255.

Palabras clave: gestión universitaria; líderes intermedios; Espacio Europeo de Educación Superior (EEES); reforma universitaria; European Credit Transfer System (ECTS).

1257-1267 HARRIS, Suzy (University of Roehampton) Challenges and Possibilities Facing European Higher Education. Papers, 2011, vol. 96, núm. 4, p. 1257-1267.

Key words: internationalisation; Bologna; university; European Union; language. 
1269-1285 CAROT, José Miguel; Conchado, Andrea (Universidad Politécnica de Valencia); MORA, José-Ginés (University of London); VILA, Luis E. (Universidad de Valencia)

La opinión de los graduados europeos sobre la universidad cinco años después de haber finalizado sus estudios. Papers, 2011, vol. 96, núm. 4, p. 1269-1285.

Palabras clave: competencias; Espacio Europeo de Educación Superior; estudios universitarios; titulado superior.

1287-1306 EliAS ANDREU, Marina (Universitat Autònoma de Barcelona)

Valoració dels estudiants universitaris sobre la incorporació de la Universitat Autònoma de Barcelona a l'Espai Europeu d'Educació Superior. Papers, 2011, vol. 96, núm. 4, p. 1287-1306.

Paraules clau: estudiants universitaris; Procés de Bolonya; aproximacions a l'aprenentatge; aprenentatge estratègic.

1307-1331 FACHELLI, Sandra; PlanAS, Jordi (Universitat Autònoma de Barcelona) Equidad y movilidad intergeneracional de los titulados universitarios catalanes. Papers, 2011, vol. 96, núm. 4, p. 1307-1331.

Palabras clave: titulados universitarios; diferencias generacionales; mercado de trabajo; movilidad laboral; Cataluña.

\section{Articles Miscel-lànic}

1335-1362 Martín Artiles, Antonio; López-Roldán, Pedro; Molina, Óscar (Universitat Autònoma de Barcelona)

Movilidad ascendente de la inmigración en España: ‘asimilación o segmentación ocupacional? Papers, 2011, vol. 96, núm. 4, p. $1335-1362$.

Palabras clave: inmigración; movilidad ocupacional; trayectorias; capital humano; segmentación; salarios; antigüedad; contrato de trabajo; empresa; sector de actividad; asimilación ocupacional.

1363-1385 Brunet, Ignasi; BalTAR, Fabiola; Gregori Gomis, Aleix (Universitat Rovira i Virgili)

L'anàlisi transaccional de l'empresa. Papers, 2011, vol. 96, núm. 4, p. 1363-1385.

Paraules clau: costos de transacció; racionalitat limitada; institucions; relació d'agència. 


\section{Notícies}

1389-1392 In Memoriam. Daniel Bell (1919-2011)

\section{Ressenyes}

1393-1396 Alexander, Jeffrey C. The Politics of Performance: Obama's Victory and the Democratic Struggle for Power (Josetxo Beriain).

Normes de publicació a Papers. Revista de Sociologia

Normas de publicación en PAPERS. ReVISTA De SOCIOlOgia

Guidelines for publication in PAPERS. REVISTA DE SOCIOLOGIA 